\title{
Port Logistics in West and Central Africa: A Strategic Development under Globalization
}

\author{
Regine Adele Ngono Fouda', Nana Darcis Romeo' ${ }^{2}$, Muhammad Azizi ${ }^{3}$, S. Rick Fernandez \\ ${ }^{1}$ Department of Logistics Management \& Engineering, Shanghai Maritime University, Shanghai, China \\ ${ }^{2}$ Department of Business \& Marketing, East China Normal University, Shanghai, China \\ ${ }^{3}$ Department of Communication, Transport \& Management, Shanghai Maritime University, Shanghai, China \\ ${ }^{4}$ School of Management, Shanghai University, Shanghai, China \\ Email: reginemilena@yahoo.fr, tontonromeo@hotmail.com, med.smu@gmail.com, saulrick@163.com
}

Received 26 November 2013; revised 31 December 2013; accepted 7 January 2014

Copyright (c) 2014 Regine Adele Ngono Fouda et al. This is an open access article distributed under the Creative Commons Attribution License, which permits unrestricted use, distribution, and reproduction in any medium, provided the original work is properly cited. In accordance of the Creative Commons Attribution License all Copyrights (c) 2014 are reserved for SCIRP and the owner of the intellectual property Regine Adele Ngono Fouda et al. All Copyright (C) 2014 are guarded by law and by SCIRP as a guardian.

\section{Abstract}

The main idea of this study is to provide help to West and Central Africa port logistics authorities in making, evaluating and realizing their decisions on port development/management, all in an effort to guaranty port efficiency and operational brilliance to profit the different ports, their hinterlands and their related clients. Consequently, an examination is made as far as port sector is concerned, with an ever more demanding enhancement in operational efficiency. Moreover, a past research on West and Central Africa Ports, as well as an overview on port logistics was made, making it possible to determine what has been done (prospects) and what is still to be done (ineffectiveness), in prospective of a more reformed and efficient port. One of the principles of this paper is also to confer all the aspects that operate as obstacles to the WCA port's improvement and development; using thus the evaluation model called EWCA (Evaluation of West and Central Africa Ports), which gives a descriptive analysis of the present situation of the latter's port logistics, including the aid of multiple regression model to determine an impact of explanatory variables on the study probability. Applying the method of strategic development, this paper thus deals with exploring typical problems and quandaries of West and Central Africa ports. The findings suggested how to fight back or overcome the constrictions and strangulations; enabling West and Central Africa port logistics attain their desired strategic development aims, despite the ineffectiveness. Tremendous efforts were made, giving a vital shoot on African economy and development; even though there is still a lot to do, for the data and variables showed how the port logistics augment and descend frequently without a long period of stability.

\section{Keywords}

Port Logistics; West \& Central Africa; Multiple Regression Analysis; Strategy Development 


\section{Introduction}

In general, African shipping has been largely deregulated. Therefore, many African countries are trapped in a vicious circle of high tariffs discouraging traffic and further increasing costs. Poor inland links (the lack of an integrated land distribution system, particularly for transit, impedes container traffic) and a wasteful and costly port administration/management accentuate this problematic situation. Several ports suffer from low capacity, particularly in terminal storage, maintenance and dredging capability. Moreover, many ports are poorly equipped and inefficiently operated. Container handling rates fall well below international norms. Port charges for both containers and general cargo are substantially higher than in other regions. Security standards are still extremely variable. Therefore, it is wise to build a coordinated network among WCA [1] ports in particular, to serve as a vivid platform for cooperation, information sharing and exchange of practices/knowledge, with the same aim of improving/boosting and developing/managing their port logistics sectors.

\section{The Problematic Statement (Problems and Requirements)}

A tactical development is therefore needed which could likely [2] have an impact on West and Central Africa's economy as well as its foreign traders (Allies and Clients). This as a whole could boost the entire African nation's economy and eradicate poverty and unemployment raging most countries [3]. Moreover, most West and Central African countries have been experiencing ramshackle in commodity stocks of some of their key export commodities (cocoa, coffee, rubber, oil etc.) from the entire region (UNCTAD 2010). Furthermore [4] [5], the problem of long dwelling time (engendering cargo for the port on specified time) is another gigantic constraint, hindering the West and Central Africa ports' development and has negative adverse effect on the Supply chain and logistic service in general [6]. For these motives, this paper would like to find out the following three issues related to West and Central Africa ports' development as far as port logistics and transportation in general is concerned.

1) What is the impact of West and Central Africa port modernization under globalization to the development of their economy?

2) Which port logistics disproportional factors are the most influential on West and Central Africa ports?

3) Which among them are the most significant or critical and what is the effect of tackling these problems of the critical factors of port logistics?

4) Does the elimination of these critical factors improve port logistics under the influence of globalization?

\section{Literature Review: A Synopsis of the Past Research in West and Central Africa (Strategic Development)}

The ports in West and Central Africa long-term strategic development can be defined as those ports that can "open the new world, open the gate to the future" with unparalleled locations as the gateway to the entire Africa boost (port website), these ports do not only serve landlocked countries around their neighborhood, but also the coastal countries of other parts of Africa (north, East, south) and the Global economy in general [2] [3] [7] [8].

The mission (which is the strength) of the ports of West and Central Africa can be determined as: We assist carriers to deliver their cargo to the place of destination. This elaborates the four operational functions associated with the port, which are: ship operation, transfer operation [9] [10], storage operation and gate operation.

To maintain the continuous growth and development, maximum short-term and long-term decision-making are required for the survival of the business.

Once a strategy is set-up and adopted, still, an effective and efficient [11] management is still required for its implementation because [12], a more generally accepted strategy does not necessary mean a successful one. To know if such a strategy is indeed the correct and best strategy, the following characteristics can be observed.

1) It's been base on precise, accurate and reliable data with clear real-time benefits.

2) The strategy should guarantee little/negligible uncertainty.

3) It's available and suitable for application under different conditions, and unforeseen circumstances should have a rescue and a backup measure.

4) There should be a Possibility of implementing the strategy within the resources available to the organization. 
5) Profitability is guaranteed (through good hinterland connection for the ports).

6) Competitiveness: looking into the companies weaknesses and making them the company's strength (in other words, building on the company's strength); as well as converting threats into opportunities [6].

7) Forecasting the future and being dynamic enough to adapt to the change in management (Peter Drucker).

\section{Methodology: The Evaluation of West and Central Africa Ports (EWCA)}

There are a number of types of evaluation, varying in form, the data they yield, and the situation to which they can be effectively applied. The various approaches in common use can be categorized as either empirical or statistical. The latter involves collecting and analyzing numerical data from which predictions are drawn and usually involve measuring a representative sample of the entire target group. Whereas, an empirical approach requires the collection of data derived from experience, observations and experiments. Well in this case, we will be enacting an evaluation model on West and Central Africa ports. As said before, West and Central Africa port are drenched in undisputable port logistics ineffectiveness and inequities, despite the several attempts to boost their ports abilities. To effectuate this analysis, multiple regression model is stipulated to excel the evaluation of WCA port logistics [10]. This paper's questions form the basis for the selection of tools for data analysis.

1) Which port logistic disproportional factors are the most influential on West and Central Africa ports?

2) Which among them is most significant or critical?

3) What is the effect of tackling these problems of the critical factors of port logistics?

4) Does the elimination of these critical factors improve port logistics under the influence of globalization?

\subsection{An Introduction of Multiple Regression Evaluation Model}

To answer the general questions of WCA port logistics, we are required firstly to apply the multiple regression model. The multiple regression techniques helped in performing correlation analysis of the relationship between the WCA port logistic determinants and the WCA port logistic values. In other words, the different technique looked at the WCA port logistic causative factors at a disaggregate level. Multiple Regression technique believes that there are critical causative factors that determine WCA port logistics under the influence of globalization [7].

In the multiple regression analysis, the coefficients of each port logistics ineffectiveness variables $X_{1}, X_{2}, \cdots, X_{n}$ determine the weight or influence of each causative factor. Consequently [10], a partial analysis on each causative factor is conducted to determine a change in $Y$, the dependent variable relative to $X_{1}$ when $X_{2}, \cdots, X_{n}$ are held constant. A partial analysis is also conducted to determine the values of $a, b_{1}, b_{2}$ etc., which represent the coefficients of the independent variable (causative factor). This therefore calls for the solving of 3 multiple regression equations.

$$
\begin{aligned}
& \sum Y=n a+b_{1} \sum X_{1}+b_{2} \sum X_{2} \\
& \sum X y_{1}=a \sum X_{1}+b_{1} \sum X_{1}^{2}+b_{2} \sum X_{1} X_{2} \\
& \sum X_{2} y=a \sum X_{2}+b_{1} \sum X_{1} X_{2}+b_{2} \sum X_{2}^{2}
\end{aligned}
$$

\section{Its Basic Model}

One of major output expected from the study is the overall West and Central Africa port logistics model. Respondent showed the perception of port logistic causative factor, relative to the level of ineffectiveness observed. This was modeled using a multivariate regression analysis that links port logistics to their causative factors. This is a very useful tool in dealing with variable relative to many explanatory variables to establish the relationship between each explanatory variable and the port logistics.

The basic model will look like this;

$$
Y_{p i}=A_{0}+b_{1} X_{1}+b_{2} X_{2}+b_{3} X_{3}+e i
$$

where: $p=$ is a given port;

$e=$ error; 
$i=$ port logistic ineffectiveness;

$x_{i}=$ are causative factors.

\subsection{An Evaluation Using the Multivariate Regression Analysis Model}

\subsubsection{Analysis on Multiple Regression Model Level}

The assessment of the degree of influence each causative factor has on port logistics involves the determination of the probability distribution of the cumulative rankings of the respondents on each port logistic causative variable. In other words, using the regression model to establish the relationship or indeed the correlation between each identified causative factor (the independent variable) and the dependent variable (port logistics ineffectiveness). This therefore calls for the calculation of the Beta coefficients of the multiple regression as showed a result on the following Table 1.

As earlier explained, the regression analysis will be conducted using port logistics ineffectiveness as dependent variable $(Y)$ and the identified causative factors as independent variables $\left(X_{1}-X_{12}\right)$. This is a forecasting technique, which could be adopted to forecast port logistics ineffectiveness in West and Central Africa ports. The interpretation of the results of the regression analysis lingers around stepwise multiple regression coefficient (Table 2) denoted by $\mathrm{R}$ and given by the formula.

$$
R=\frac{\frac{\sum x y-\sum x-\sum y}{n}}{\frac{\sqrt{\sum x^{2}}-\left(\sum x\right)^{2}}{n} \frac{\sqrt{\sum y^{2}}-(y)^{2}}{n}}
$$

The value of $R=-1$ indicates a perfect linear relationship between the sample value of $X$ and $Y$, with the value of $Y$ decreasing as the value of $X$ increases. The larger $X$ becomes, the smaller $Y$ becomes, and vice versa. A value of $R=+1$ also indicates a perfect relationship between $y$ and $x$ but here $y$ increases as $x$ increases. Larger values of $y$ are associated with larger values of $x$, if there is no relationship between the samples of $y$ and $x$; to zero (however, small $x$ and $y$ are components of big $X$ and $Y$ ). As R increases from 0 to -1 , the relationship between the sample value of $x$ and $y$ becomes more pronounced.

The variables to be used on the table are as follows: HCPSSL "High Costs of port for shippers \& Shipping lines" $\left(X_{1}\right)$, UDT "Undeveloped Technology” $\left(X_{2}\right)$, LCY "Low Capacity” $\left(X_{3}\right)$, ISS “Inadequate Shipping services" $\left(X_{4}\right)$, SLSCWC "Shipping line strategies coping with the constraints" $\left(X_{5}\right)$, POMMPS "Port ownership \& management mainly public service" $\left(X_{6}\right)$, CRLLDE "Containerization rate lingers low despite efforts" $\left(X_{7}\right)$, PEPPC "Port efficiency on port productivity \& cost" $\left(X_{8}\right)$, AMPLH "Awkward measure \& poor links to the

Table 1. The Approximate ranking of port logistics ineffectiveness in WCA from 1995-2010.
\begin{tabular}{ccccccccccccccc}
\hline $\begin{array}{l}\text { Years of study } \\
\text { Factors } \\
\text { (approx. \%) }\end{array}$ & HCPSSL & UDT & LCY & ISS & SLSCWC & POMMPS & CRLLDE & PEPPC & AMPLH & LCT & PCURIM & PPSM \\
\hline $1995-2000$ & 88 & $X_{2}$ & $X_{3}$ & $X_{4}$ & $X_{5}$ & $X_{6}$ & $X_{7}$ & $X_{8}$ & $X_{9}$ & $X_{10}$ & $X_{11}$ & $X_{12}$ \\
\hline 20 & 79.5 & 58 & 28 & 30 & 0.6 & 12 & 2 & 8.6 & 51 & 29 \\
$2000-2005$ & 86.5 & 49 & 72 & 61.5 & 30 & 55 & 0.85 & 12.8 & 2.8 & 7.2 & 55 & 31.5 \\
2005-2010 & 84 & 43 & 70 & 63 & 33 & 59 & 0.95 & 14 & 4 & 6 & 63 & 45 \\
Total & 1292.5 & 760 & 1107.5 & 912.5 & 455 & 720 & 12 & 194 & 44 & 109 & 845 & 527.5 \\
Average In \% & 86.17 & 50.67 & 73.83 & 60.83 & 30.33 & 48 & 0.8 & 12.93 & 2.93 & 7.27 & 56.33 & 35.17 \\
\hline
\end{tabular}

Source: A compilation of data and statistics from Cullinane and Khanna works on the Journal of Transport Economics and Policy, as well as UNCTAD review, sorted with many other authors, 2006-2010.

Table 2. Multiple regression variables $(X)$ and $(Y)$.

\begin{tabular}{rcccccccccccc}
\hline$X$ Diff. Years & 15 & 15 & 15 & 15 & 15 & 15 & 15 & 15 & 15 & 15 & 15 & 15 \\
\hline$Y$ Total in \% & 86.17 & 50.67 & 73.83 & 60.33 & 30.33 & 48 & 0.8 & 12.93 & 2.93 & 7.27 & 56.33 & 35.17 \\
\hline
\end{tabular}


hinterlands" $\left(X_{9}\right)$, LCT “Location constraint” $\left(X_{10}\right)$, PCURIM "Port capacity usually results from Inadequate maintenance" $\left(X_{11}\right)$, PPSM "Port performance in WCA, slow motion" $\left(X_{12}\right)$, and the studied carried is based on a 15 years plan (1995-2010) [13] [14]. The factors of these different years are portrayed on approximate percentage [9] of the gravity of the situation in West and Central Africa Ports logistics.

Therefore, following the formulae (4.e) of multiple regression coefficient denoted by $R$, the next table expresses the variables $(X)$ and $(Y)$.

We have this result from the table: however, these results are the abrupt components of the above formula applied to this specific case.

$\sum_{\text {riables }} y=464.54, \sum x=180, \sum x y=15, \sum y=6968.1, \sum y^{2}=27007.045, \sum x^{2}=2700, n=12$ va-

Therefore, the value of $R=0.084488$.

\subsubsection{Identification of the Critical Factors for WCA Port Logistics from the Regression Analysis}

The mini-regression statistics as showed above (Table 3) shows a strong correlation existing between port logistics values and the identified causative factors of ineffectiveness. The $R$-value stood at 0.084488 and the coefficient of determination also gave a value of 0.007138 . This implies that the causative factors $X_{1}-X_{12}$ is accountable for WCA port logistics ineffectiveness experienced at the ports.

Considering the factors depicted on the mini-regression table, the variables $X_{7}, X_{8}, X_{9}, X_{10}$ are very low in percentage because of their reverse (in percentage) highly contribution in the ineffectiveness of WCA port logistics (the most influential factors). The other variables define the different degree of ineffectiveness according to their critical percentages. I present $X_{5}$ as next critical factor with a percentage of $30.33 \%$, followed by $X_{12}$ with a percentage of $35.17 \%, X_{6}$ with a percentage of $48 \%$, while the other following factors are mostly WCA ports prominent factors. $X_{2}$ with a percentage of $50.67 \%, X_{11}$ with a percentage of $56.33 \%$, $X_{4}$ with a percentage of $60.83 \%$, factor $X_{3}$ with a percentage of $73.83 \%$ and finally $X_{1}$ with a percentage of $86.17 \%$.

\subsubsection{Discussions of Some of the Critical Variables}

The identification of variable $X_{9}$ or Awkward Measure and Poor Links to the Hinterlands as one of the most critical factors is justified. Normally, there should be a boost up in direct link between terminals, a fixed capacity by trains [13], an enormous stability on timetable, a fixed agreement in time and quality of services [15], and a more integrated price, therefore (transport + handling in dry port + distribution). We noticed that a seaport could be connected and reliable to one or more dry ports in the hinterland and or with other seaports in the foreland, creating an unswerving port network [1]. However, this is not the fact in WCA ports. They are demoted by poor links in hinterland, hindering distribution of products/containers and stalling the port activities. Worst of it all, the delays encountered during hinterland links (transit traffic registered to LLC of WCA amount to approx. $\$ 3$ million) are been added unto the beneficiary bills, rendering the cost more expensive.

The next factors are $X_{10}$ Location Constraint and $X_{2}$ Undeveloped Technology. These duo combination variables are important to be addressed if WCA port efficiency needs to be improved. Even though most WCA ports are situated on the coast, the cities in which they are built are city-centers. Due to this location constraint, there is a lot of congestion around and within the port sector. Moreover, though the private operators have-invested much resources in the procurement of cargo handling equipment in both quantity and quality, the investment result or effect is not yet significant. The terminal operators still rely mostly on the outdated and obsolete equipment inherited from WCA ports authority during the concession arrangement. This factor is the bane of efficient port operation in WCA, so as factor $X_{5}$.

Other factors such as $X_{3}$ Low Capacity and $X_{11}$ Port Capacity usually Results from Inadequate Maintenance are also crucial. The port capacity in most WCA ports is used at $80 \%$ due to the fact that a larger capacity calls for greater care and finances [16]. There is a dredging maintenance problem in most ports rendering its inadequacy.

Table 3. Mini-regression statistic of WCA ports logistics.

\begin{tabular}{ccccccc}
\hline \multicolumn{7}{c}{ Change Statistics } \\
Model & $R$ & $R$ Square & Adjusted $R$ Square & $R$ Square Change & Df1 (defined variables) & Df2 (defined model) \\
\hline I & 0.084488 & 0.007138 & 0.50488 & 0.007138 & 12 & I \\
\hline
\end{tabular}


Worst of all, there are fewer gantry cranes in WCA developing ports terminals such as, Abidjan has 3 cranes, while Douala, Tema both have 2 cranes. Moreover, $X_{12}$ Port Performance in WCA, slow Motion completes afore mentioned inadequacy. The number of crane per hour moved (containers) is $10-20$ hours; worst is witnessed in Dakar port with 7 - 10 hours. There is also inadequacy in trucks cycling in the ports, estimated at 10 hours per load.

Port Efficiency on Port Productivity and Cost $X_{8}$ and High Costs of Port for Shippers and Shipping Lines $X_{1}$ are justified factors observed in WCA ports. Despite all efforts furnish in WCA ports, dwell time is still a massive strangulation. In the port of Abidjan, it goes up to 7 days, while in Douala doubles to 17 days. Moreover, shippers and shipping lines find the WCA ports costly as mentioned above. Due to congestion of the port inabilities, the shippers are compelled to pay high cost. For example, a shipping line had to pay about $\$ 5$ million, due to a 146 days lost between Europe and Africa [17] [18]. Furthermore, Inadequate shipping services $X_{4}$ pushed the defect of WCA ports. This is because, even though docking vessels increased in WCA ports, ships can't excess 2500 TEU, most ships sail with 1000 - 2000 TEU.

Ports in WCA are limited, limited in resources, limited in its administration, limited in its operation [19]. This is mainly so due to the fact that, Port Ownership and Management are mainly Public Service $X_{6}$ [6]. With the government directing and managing the port, it can only land to port disruption and ineffectiveness, pushing forth a lot of traffic along the port due to unfitness of the authority. Moreover, despite all strategy methods implemented by WCA ports authority, containerization rate still lingers low $X_{7}$.

\subsection{Establishing the Evaluation Model of WCA with Multiple Regression}

Following the above discussions on the different critical variables of the West and Central Africa port logistics ineffectiveness, an establishment is put forth as an evaluation model, which flow alongside the multiple regression equation below (however, this equation is an approximation result of variables from Table 1 of port logistics ineffectiveness ranking in WCA).

Port Logistics of West and Central Africa $=-61.989-0.476 X_{1}+13.210 X_{2}-3.472 X_{3}+2.424 X_{4}+3.337 X_{5}+$ $0.031 X_{6}-0.728 X_{7}+1442.562 X_{8}+3177.238 X_{9}-10.342 X_{10}-0.648 X_{11}+1037.927 X_{12}+e$.

The equation suggests that port logistic ineffectiveness will augment on average by 0.476 of a unit decrease in $X_{1}$, increase on average of 13.210 of a unit in $X_{2}$, augment on an average by 3.472 of a unit decrease in $X_{3}$, augment on average by 2.424 of a unit increase in $X_{4}$, an augment on average by 3.337 of a unit increase in $X_{5}$, an increase on average by 0.031 of a unit decrease in $X_{6}$, an augment on average by 0.728 of a unit increase $X_{7}$, an augment on average of 1442.562 of a unit increase in $X_{8}$, an augment on average by 3177.238 of a unit increase in $X_{9}$, an augment on average by 10.342 of a unit increase in $X_{10}$, an augment on average by 0.648 of a unit increase $X_{11}$, finally an augment on average by 1037.927 of a unit increase in $X_{12}$.

Therefore, summarizing the logic of multiple regression evaluation model, despite the ineffectiveness of West \& Central Africa port logistics [10], they have gone through tremendous efforts to boost their ports sectors, giving a vital shoot on the African economy and development [3]. Nevertheless, there is still a lot to do, for the data and variables above show how the latter's port logistics augment and descend frequently, without a long period of stability.

\section{Strategic Execution}

Strategic execution is defined as the practice of bringing a strategy to culmination. Companies in general site strategic execution as a crown priority, but few often agree on how to make it happen. Therefore, having to relate strategic execution in West and Central Africa ports will benefit the latter from escalation capabilities of; strategy transformation in the ports sector, business and financial decision making from the port administrators [19], cultural changes at the port's environment, implementing key performance indicators, merger integration for better development, safety and quality at the pace of global trend, and finally bequeath operational [8] [19] excellence making the ports rise to an international dimension.

\subsection{Construction of an Organization Frame Work}

The port administrators of WCA and their Government need highly qualified managers with advance foresights, capable of forecasting and having the ability to optimize operations and minimize obstacles. 


\subsection{Establishment of Development Plan}

Strategy Planning is the key to resolve inefficiency, poor performance, and inadequate terminal operations. This however requires the setting of realistic objectives, particularly with its equipment.

\subsection{Struggles for Policy Support}

Unfair measures and mistreat of policies that distort performance in business should be discarded, while proactive measures set in due place [20] [21]. Unreliable contract and postponement of projects should be avoided.

\subsection{Determine Bottleneck of Development}

Resolving bottleneck can help West and Central Africa ports administrators attract financial support from large multinational operators and shipping lines.

\subsection{Outsource Intricate Technical and Engineering Work}

West and Central Africa Ports should endorse outsourcing of some of the intricate technical and engineering works to private sectors or to competent contractors, especially in the area of dredging. They should also contract the ship lanes for constant maintenance and repair of the quay.

\subsection{Collaboration}

West and Central Africa ports should carry out port reforms [20]-[22] and ensure collaboration both at local and international levels.

\section{Conclusions and Self Prospect}

\subsection{Conclusions}

Results for Questions

RQ1: What is the impact of West and Central Africa port modernization under globalization to the development of their economy?

African nations are dwelling with poverty, as a result of their frequent instability in politics and economy. West and Central Africa in an attempt of fighting this strangulation have been determined to modernize their ports infrastructure, so as to improve their economy standard. However, the port logistic of WCA port has been in constant alert due to much ineffectiveness. Following the results on chapter 3, one can say that the ineffectiveness of WCA port logistics is drastic but it is modernized under globalization with a good strategic plan and framework.

RQ2: Which port logistic disproportional factors are the most influential on West and Central Africa ports?

As far as West and Central Africa port logistics is concerned, there are many influential factors of ineffectiveness, e.g. poor hinterland links, out-dated machineries, poor infrastructure [6] [23], inadequate shipping services, benchmarking, low maintenance of port area/zone, port officials corruption, high custom fees, slow motion in port performance, containerization linger low despite efforts of revival, low capacity, and undeveloped technology.

RQ3: Which among them are the most significant or critical and what is the effect of tackling these problems of the critical factors of port logistics?

According to the multiple regression and the other evaluation models, the most significant or critical effect of West and Central Africa port logistic among others are poor links to hinterland, outdated machinery, low technology and port capacity. However, the highest bid problem is the containerization rate, which lingers low despite the effort of stability (this cracks out due to the fact that, this problem is the tree that stems from and carries out many sub ordinary problems, such as high dwelling time, long hours on turn around ships, congestion in the port facilities etc.). For example, from 2008-2009, container traffic dismayed among WCA developing ports; Cote d'Ivoire was at $-5.13 \%$, Senegal $-4.72 \%$, and Cameroon $-10.00 \%$.

Therefore, to tackle this problem, there is a necessity of a rigid strategic plan process, followed by a frame- 
work, which can actually, on a first round, perk up a solution for the defect. Also, the problem of undeveloped technology crashes all hopes due to the fact that, a proper port can't actually function on a global trend without adequate machineries and technology. A simple fact is that, the port of Douala and Abidjan for example has got just 2 gantry cranes to move all containers on docking ships. This takes more time and causes congestion around the port area, increasing high cost for shippers and shipping lines on their goods. Solving such a factor will demand a lot of time and patience due to the fact that, WCA port authority, after establishing a strategic plan, will need to get some machinery aid from their business partners of developing countries such as China, so as to install new technology and provide ability skills for the operators. This surely needs time and patience. However, this cannot be a vital guarantee of success and immediate change of congestion problems and port maintenance.

Furthermore, another means of tackling the problems can be that, medium-size ports in the region could also be serious competitors for becoming hubs. Indeed, decisions on transshipment centers in WCA will reflect a wide range of additional business considerations by ocean carriers, including the capacity of the ports to handle significantly increased traffic, draft and infrastructure consideration, productivity to minimize turnaround time, and country stability.

RQ4: Does the elimination of these critical factors improve port logistics under the influence of globalization?

After the final result of regression analysis and the facts from the strategic formation and implementation, a lot have been put forth to improve west and Central Africa port logistics under the influence of globalization. However, one cannot certify that the eradication of all these ineffectiveness can amount to a new developed WCA as a whole, and a boom in their economy. Nevertheless, a lot will have increased, internally (port premises) as well as globally (in their respective WCA countries and other world countries in general), where business clients and collaborators from around the world will often come back for eventual business.

This is to stipulate that, current challenges may become opportunities in a long range, as these developments should be examined over time and result in more efficient port and transport operations, which should significantly decrease transport costs for West \& Central African economies.

\subsection{Self Prospect}

- West and Central Africa government and port authority should aim at facilitating procedures and controls in ports, such as procedures affecting turnaround time, dwelling time and handling costs. Otherwise, port attractiveness will be seriously limited. The introduction of a community-based system may help in this regard.

- West and Central Africa government and port authority should tend at improving port access in view to develop multimodal transport. Areas around ports are usually congested and worst of all pitiable road infrastructures. To improve port access may therefore have a positive impact on city economic activity and port efficiency.

- West and Central Africa government and port authority should develop knowledge sharing between ports and countries on current port improvement in their region. The Port Management Association of West and Central Africa (PMAWCA) could become a suitable arena for these exchanges of views.

- Port authority and administration should tend at increasing competition among shipping lines in countries where informal barriers to market entry still prevail.

- Furthermore, port authority and administration should also tend at facilitating trade and land transport outside the port on the main trade corridors.

- WCA ports authority should foster private sector participation both to provide investment for new installations and equipment, as well as transferring technical know-how and more efficient terminal management.

- Also, Striving for efficient ports must be complemented by associated measures to increase transparency and reduce corruption in customs administration.

- The West and Central Africa ports, like all world ports, must create port community systems not only to improve productivity and efficiency (and thereby reduce costs), but also to respond to the growing importance of future obligation in supply chain security.

- Moreover, to be competitive, a port must offer high productivity of traditional port services and add value services to the goods. The key strategies therefore will be:

- Reduction of the generalized cost of transport,

- The port as a logistics hub, as well as development of a ZAL (zone of added logistics) in or around the port area,

- Development of dry ports and inland terminals + port networking. 


\section{References}

[1] Dey, P.K. (2004) Benchmarking project management practices of Caribbean organization using AHP. Benchmarking: An International Journal, 9, 326-356.

[2] Clark, X., Dollar, D. and Micco, A. (2004) Port efficiency, maritime transport costs and bilateral trade. Journal of Development Economics, 75, 417-450. http://dx.doi.org/10.1016/j.jdeveco.2004.06.005

[3] Cambron, K.E. and Evans, G.W. (1991) Layout design using the analytic hierarchy process. Computers \& IE, 20, 221-229.

[4] Beresford. A.K.C., Gardner, B.M., Pettit, S.J., Naniopoulos, A. and Wooldridge, C.F. (2004) The UNCTAD and WORKPORT models of port development: Evolution or revolutions? Maritime Policy and Management, 31, 93-107. http://dx.doi.org/10.1080/0308883042000205061

[5] Arvis, J.-F., Raballand, G. and Marteau, J.-F. (2010) The cost of being landlocked. The World Bank. Pages, Washington DC, $99 \mathrm{p}$.

[6] Nijkamp, P. (2005) Port reform and concessioning in developing countries. Maritime Economics \& Logistics, 7, 141155.

[7] Slack, B., Comtois, C. and McCalla, R. (2002) Strategic alliances in the container shipping industry: A global perspective. Maritime Policy and Management, 29, 65-76. http://dx.doi.org/10.1080/03088830110063694

[8] Acciaro, M. (2008) Risk management in port operations, logistics and supply chain security. Maritime Economics \& Logistics, 10, 325-327.

[9] Bell, M.G.H. and Khalid, B. (2007) The port sector in South Africa: Towards an integrated policy and institutional reform. World Bank, Washington DC.

[10] Aldrich, J. (2005) Fisher and regression. Statistical Science, 20, 401-417.

[11] Sánchez, R.J., Hoffmann, J., Micco, A., Pizzolitto, G.V., Sgut, M. and Wilmsmeier, G. (2003) Port efficiency and international trade: Port efficiency as a determinant of maritime transport costs. Maritime Economics and Logistics, 5, 199-218. http://dx.doi.org/10.1057/palgrave.mel.9100073

[12] Cullinane, K. and Khanna, M. (2000) Economies of scale in large containerships: Optimal size and geographical implications. Journal of Transport Geography, 8, 181-195. http://dx.doi.org/10.1016/S0966-6923(00)00010-7

[13] Ludema, M.W. (2008) Supply chain configuration management. IEEE International Conference on Service Operations and Logistics, and Informatics, 2508-2513.

[14] Notteboom, T.E. (2006) The time factor in liner shipping services. Maritime Economics and Logistics, 8, 19-39. http://dx.doi.org/10.1057/palgrave.mel.9100148

[15] Belton, V. and Gear, T. (1983) On a short-coming of Saaty’s method of analytic hierarchies. Omega, 228-230.

[16] Hill, T. and Westbrook, R. (1997) SWOT analysis: It's time for a product recall. Long Range Planning, 30, 46-52.

[17] Devlin, J. and Yee, P. (2005) Trade logistics in developing countries: The case of the Middle East and North Africa. The World Economy, 28, 435-456.

[18] Menon, A., et al. (1999) Antecedents and consequences of marketing strategy making.

[19] Pallis, A.A. (2007) Greek maritime transport: A view from within. In: Idem, Ed., Maritime Transport: The Greek Paradigm, Research in Transportation Economics, No. 21, Elsevier, London, 1-22.

[20] Omran, M.F. (2012) Uncovering the relationship between the degree of transparency and the level of trade logistics in the Middle East and North Africa. African Journal of Economic and Sustainable Development, 1, 377.

[21] McLellan, R. (2006) Liner shipping development trends. Maritime Policy \& Management, 33, 519-525.

[22] Van Niekerk, H.C. (2005) Port reform and concessioning in developing countries. Maritime Economics and Logistics, 7, 141-155. http://dx.doi.org/10.1057/palgrave.mel.9100129

[23] Pearson, K., Yule, G.U., Blanchard, N. and Lee, A. (1903) The law of ancestral heredity. Biometrika (Biometrika Trust) 2, 211-236. 